\title{
Modelagem paramétrica para simulação do desempenho da iluminação natural e termo-energético da edificação
}

\author{
- Alexandre Reis Felippe \\ UFSC/PPGEC, Brasil \\ alexandre@labcon.ufsc.br \\ - Raphaela Walger da Fonseca \\ UFSC/ PosArq, Brasil \\ raphawf@gmail.com \\ Letícia Niero Moraes \\ UFSC/ PosArq, Brasil \\ letinierom@gmail.com \\ - Fernando O. Ruttkay Pereira \\ UFSC/ PosArq / PPGEC, Brasil \\ feco@arq.ufsc.br
}

Parametric modeling for the simulation of daylight and thermo-energetic performance of buildings

\begin{abstract}
This study comprises the developing process of a parameterization algorithm in grasshopper forbuilding daylight and energy integrated simulation considering the main daylighting key-variables. DIVA for Grasshopper plugin was used to carry out the simulations in Radiance/Daysim and Energyplus. The algorithm enables several sample simulationswhile improvingprocess agility, providing a graphical output of the models andminimizing the possibility of human errors. Acase study considering three different samples simulation was proposed aiming to test the algorithm. Its resultswere used to evaluatethe sample size required to train an artificial neural network for modeling daylighting harvesting potential.
\end{abstract}

Keywords: Parametric Modeling, Daylight, Thermo-energetic, Grasshopper, DIVA

\section{Introdução}

A avaliaçãoglobal dos efeitos do aproveitamento da luz natural no desempenho energético de edificações é complexa devido ao seu impacto duplo: i) no sistema de iluminação artificial e ii) no de condicionamento de ar. Devem-se computar a diminuição do uso do sistema de iluminação artificial e do calor gerado por esse sistema ao longo do ano, bem como os ganhos térmicos da radiação luminosa. Assim, a simulação computacional surge como uma alternativa para modelar estes efeitos. A integração entre programas de simulação termo-energética e programas de simulação de iluminação natural faz-se necessária, visto que os métodos de cálculo de iluminação natural incorporados por programas de simulação termo-energética até o momento apresentam limitações quanto à modelagem do fenômeno (Didoné, 2009; Ramos e Ghisi, 2010; Versage, Meloe Lamberts, 2010).

O método do raio traçado, utilizado por programas com base no Radiance(Reinhart;Walkenhorst, 2001), oferece vantagens na modelagem do desempenho físico dos raios de luz e seus efeitos de acordo com as propriedades espectrais dos materiais para qualquer complexidade geométrica (Didoné, 2009; Ramos e Ghisi, 2010; Versage, Melo e Lamberts, 2010). A desvantagem desse método é o tempo de simulação. A integração entre o programa de simulação termoenergéticaEnergyPlus (Crawley, 2001) e o Daysim-Radiance (Reinhart, 2010) de iluminação natural é a combinação mais difundida em pesquisas da área, devido à consistência dos programas. O plug-in DIVA for Rhino (Jakubiec; Reinhart, 2011) possibilita esta integração obtendo os dados de padrão de uso do sistema de iluminação artificial através do DaysimRadianceetransferindooresultadoparaoEnergyPlusfornecer o consumo total da edificação através da simulação termoenergética. Entretanto, a simulação de grande quantidade de modelos paramétricos utilizando os dois programas é um processo complicado e demorado, requerendo a aplicação de ferramentas de simulações paramétricas para viabilizar este tipo de estudo.

Os recentes avanços na ciência da computação e as exigências de comprovação do desempenho das edificações impulsionaram o desenvolvimento de métodos de simulação onde se adota uma abordagem integrada de sistemas generativos, processos de parametrização e otimização. A introdução de algoritmos de parametrização, aliados a ferramentas computacionais no processo projetual, permite a rápida exploração de grandes quantidades de alternativas, aumentando as possibilidades de investigação de diferentes variáveis, para avaliações de diversos fenômenos relacionados a iluminação natural e eficiência energética.

Estudos recentes tem demonstrado o uso potencial das ferramentas para de análise do desempenho do envelope construtivo para otimização energética ou aspectos visuais (Andersen,2010; Torres; Sakamoto,2007). Wright e Mourshed (2009) realizaram investigação da influência da forma, número 
e posição das aberturas no consumo energético, conduziram estudos da disponibilidade de radiação solar em ambientes urbanos (Choo; Janssen ; 2013; Giani et Al., 2013; Lobaccaro; Frontini, 2014; Lobaccaro; Masera, 2014a; Vannini, 2011).

Devido ao caráter repetitivo dos procedimentos, estes métodos são geralmente automatizados por programação computacional. Dentre as ferramentas disponíveis,destacase o plug-in Grasshopper (Rutten, 2011), do programa de modelagem tridimensional Rhinoceros (Mcneel, 2014), que permite a geração de modelos paramétricos. As simulações de disponibilidade de luz natural e cargas internas são realizadas no plug-in DIVA for Grasshopper (Jakubiec; Reinhart, 2011) do mesmo programa.

Diante do exposto, o objetivo deste trabalhoé desenvolver um processo de parametrização para viabilizar a simulação de diferentes amostragens, considerando as principais variáveischave de iluminação natural e consumo energético.

\section{Método}

O método adotado utiliza o plug-in Grasshopper para a elaboração de um algoritmo de parametrização que permite a visualização das variações nos modelos bem como a obtenção de resultados numéricos das simulações de iluminação natural e termo-energética. O conceito de proposição da ferramenta consistiu em três etapas: 1) Definição das variáveis de entrada; 2) Concepção do algoritmo de parametrização no Grasshopper considerando possibilidades de avaliação de conjuntos amostrados aleatória ou direcionada e algoritmos genéticos evolucionários além da simulação propriamente dita; e 3) Gravação dos resultados (ver Figura 01).

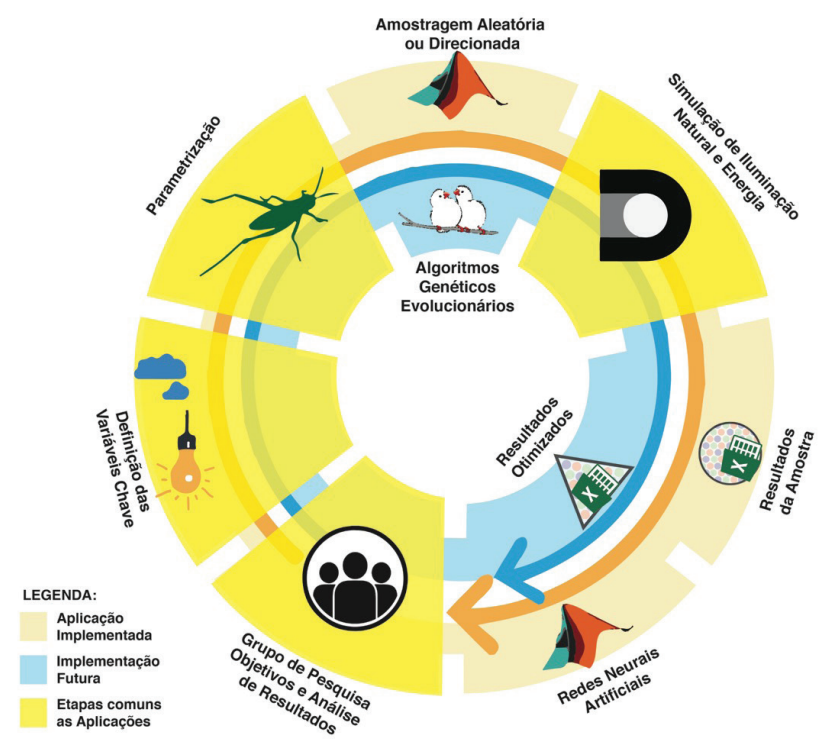

Figura 1: Esquema conceitual do algoritmo. Fonte: Fonseca (2015).

\section{Definição das Variáveis}

A primeira etapa do método foi a definição das variáveischave da iluminação natural sob o enfoque da sua influência no consumo energético. Foram elencadas onze variáveis, conforme destacado na Figura 02, com base no Quadro de Análise de Iluminação Natural proposto no relatório final de Medidas de Iluminação Natural elaborado para o PIER - California Energy Comission para analisar ferramentas de avaliação do desempenho da iluminação natural em edificações (Heshong, 2011).

Foram identificadas e consideradas para este estudo, variáveis relacionadas à descrição do espaço, como a geometria e refletância das superfícies; variáveis relacionadas ao contexto do espaço, tais como localidade e obstrução do entorno e variáveis do desempenho do espaço com influência no sistema de iluminação artificial e no balanço térmico da edificação.Para a definição dos valores de cada variável priorizou-se a diversidade como critério de seleção, procurando-se abranger soluções arquitetônicas extremas. O percentual de abertura da fachada (PAF), por exemplo, assumiu os valores mínimo e máximo segundo a literatura, $20 \%$ e $80 \%$, respectivamente, e um valor intermediário, $50 \%$. O total das combinações de variáveis contempladas pelo algoritmo resultam em 10.450 .944 casos.

Para que o algoritmo fosse capaz de simular qualquer modelo dentre as combinações possíveis, foi necessária a parametrização de cada uma das variáveis individualmente. Estas variáveis, podem ser lidas a partir de arquivos na extensão *.csv em que cada caso esteja disposto em uma linha e os valores das variáveis estejam dispostos em colunas de acordo com a ordem reconhecida pelo algoritmo. Desta forma, diferentes tipos de amostragens, inclusive geradas em outros programas, como por exemplo o Matlab, podem ser utilizadas como dado de entrada para o algoritmo desenvolvido no Grasshopper.

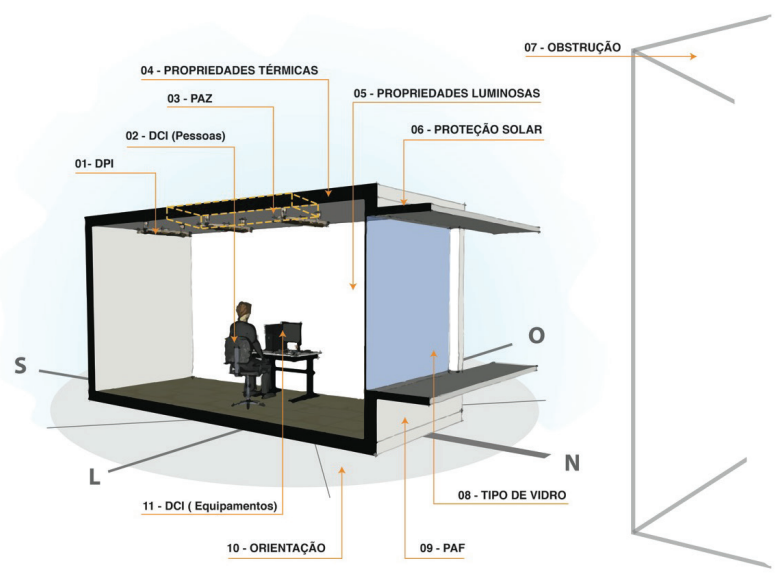

Figura 2: Variáveis-chave parametrizadas no algoritmo.

\section{Concepção do Algoritmo no Grasshopper}

O algoritmo desenvolvido no Grasshopper interpreta os dados obtidos dos arquivos na extensão *.csv, transformando os valores das variáveis em dois modelos tridimensionais similares, porém distintos na forma de modelagem. Um dos modelos é utilizado para simulação de iluminação natural, 


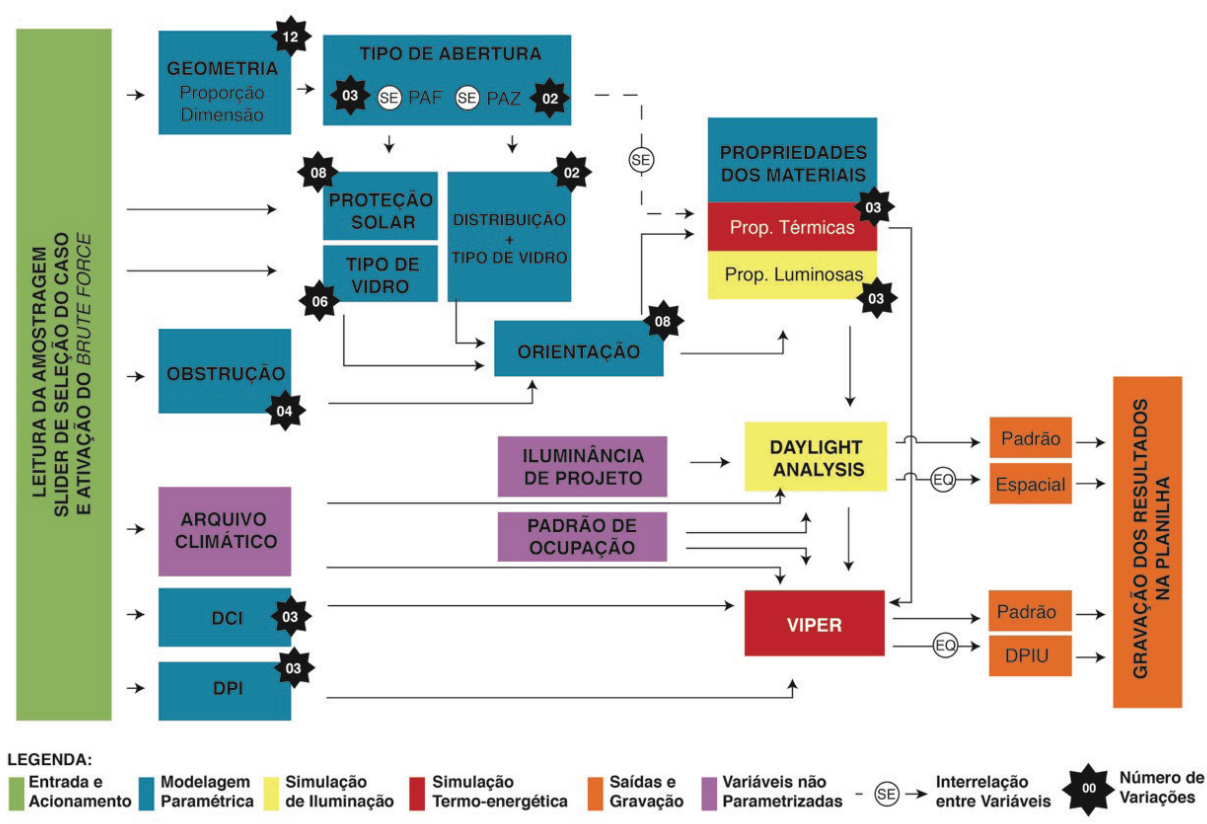

Figura 3: Esquema da implementação do algorítmo.

enquanto o outro é utilizado para análise de consumo energético. As simulações de disponibilidade de luz natural e de desempenho termo-energético são realizadas no plug-in DIVA for Grasshopper (Jakubiec; Reinhart, 2011), que integra as duas simulações por meio dos componentes Daylight Analysis e VIPER.

Este algoritmo foi estruturado em cinco grupos conforme as funções a serem exercidas: a) leitura de dados de entrada e acionamento, b) modelagem paramétrica da edificação, c) simulação de iluminação natural, d) simulação termo-energética e) saídas (desempenho do ambiente). A Figura 03 ilustra a estrutura do algoritmo. Destacando as funções mencionadas.

a) Leitura de dados de entrada

Os dados das planilhas são obtidos do arquivo *.csv por meio do componente File e então separados em sub-listas das variáveis através do componente Split (ver Figura 04).

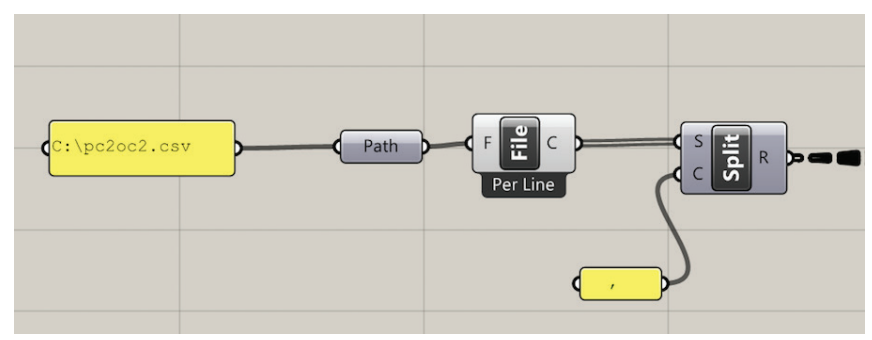

Figura 4: Leitura dos dados do arquivo *.csv e separação em sub-listas.

Cada coluna dessas listas corresponde a um valor de variável de um caso a ser simulado. A codificação das variáveis foi tratada de forma qualitativa e quantitativa. As variáveis classificadas como qualitativas foram tratadas de forma binária (ex.: 0 ou 1) ou de forma codificada (ex.: 1, 2, $3,4)$, em que cada valor adotado corresponde a uma solução de projeto, como por exemplo para as aberturas zenitais (ver Figura 5).Já as variáveis quantitativas têm sua codificação atribuída a valores reais,a exemplo dos ângulos de obstrução (ex.: $30^{\circ}, 45^{\circ}, 90^{\circ}$ ).

Com o componente List Item, o caso a ser simulado é selecionado por meio de uma Slider e os valores das variáveis são encaminhados para modelagem paramétrica da edificação e aplicação das propriedades dos materiais.

Para viabilizar simulações de vários modelos em sequência evitando a necessidade de alterar manualmente o caso na Slider de acionamento da simulação utilizou-se o componente Brute Force do plugin para o grasshopper TTollbox.

b) Modelagem paramétrica da Edificação

As primeiras variáveis programadas no algoritmo foram as que dão a dimensão e proporção ao ambiente analisado. Os valores de dimensão são multiplicados pelos valores de proporção e então atribuídos ao comprimento, largura e altura da modelagem de um ambiente retangular.

O percentual de abertura da fachada (PAF) foi parametrizado por meio da variação da altura de peitoril da janela, mantendo a altura da verga fixa de modo a obter-se uma área de abertura de 20\%, 50\%, 80\% para ambientes com pé-direito simples ou duplo (ver Figura 04). Adicionalmente, foi programada uma opção sem janela lateral para casos com abertura zenital.

O percentual de abertura zenital (PAZ) é calculado com base nas dimensões da área de cobertura da edificação. Primeiramente o algoritmo verifica se a abertura é do tipo centralizada (1 abertura) ou distribuída (4 aberturas), em seguida, o tamanho das aberturas é calculado de modo a 
atender o PAZ especificado combinado com o tipo de vidro utilizado. Para o modelo de simulação de iluminação natural é criada uma abertura no plano do teto e uma nova face para representar o vidro, enquanto que para o modelo de simulação energética a representação do vidro pode ser feita com uma face sobreposta ao plano do teto. Esta diferenciação se faz necessária para atender as especificidades dos programas Radiance/Daysim e Energyplus.

O tipo de vidro aplicado à abertura zenital está relacionado com a porcentagem de abertura, adotando um vidro claro comum para aberturas de $2 \%$ e um vidro difusor para aberturas de 40\% (ver Figura 05).

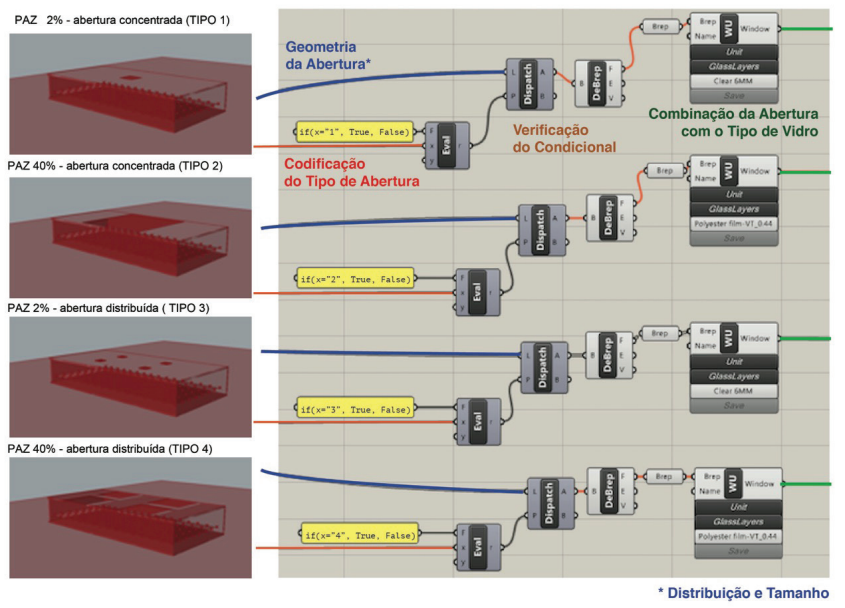

Figura 5: Aplicação do tipo de vidro em relação ao caso do PAZ (porcentagem de abertura).

Ainda no caso de modelos com aberturas zenitais outras variáveis são encadeadas ou inter-relacionadas, logo, quando há qualquer tipo de abertura zenital, não há nenhuma abertura lateral. Da mesma forma, quanto às propriedades térmicas da cobertura, a superfície da cobertura não pode assumir condição adiabática, uma das soluções para modelagem de ambientes localizados em pavimentos intermediários de um edifício com abertura lateral em que não há trocas térmicas da cobertura do ambiente com o exterior..

O algoritmo também leva em consideração a existência de elementos de proteção solar horizontais e verticais com ângulos de sombreamento de $30^{\circ}, 45^{\circ}$ e $60^{\circ}$, respectivamente (ver Figura 07). A manutenção destes ângulos é feita através do comprimento das aletas que é calculado com base nas tangentes dos três ângulos amostrados.

As refletâncias de paredes, piso e teto são tratadas por meio de funções condicionais utilizando os componentes Evaluate e Dispatch, habilitando a aplicação dos materiais do Radiance/ DIVA conforme o valor atribuído à variável no modelo.

A variável densidade de carga interna (DCI) contempla grupos de valores com cargas internas provenientes da ocupação e equipamentos. O código do grupo de DCI a ser simulado é convertido em valores correspondentes ao número de pessoas por unidade de área $\left(\mathrm{m}^{2}\right)$ e potência de equipamentos $(\mathrm{W})$ por unidade de área $\left(\mathrm{m}^{2}\right)$ Estes valores são encaminhados diretamente para o componente de simulação termo-energética (VIPER).

A condição de obstrução externa considera existência ou não de uma edificação em frente à fachada principal do modelo a ser simulado. Para a parametrização desta variável, fixou-se um a altura da edificação que causa obstrução enquanto a posição no eixo $Z$ do ambiente de análise pode ser alterada, de modo a garantir as seguintes situações: ambiente térreo sem obstrução e contribuição da refletância do piso externo, ambiente térreo com obstrução e contribuição da refletância do piso externo, ambiente localizado no meio do edifício com obstrução e ambiente localizado no topo do edifício sem obstrução.

Para considerar diferentes orientações da fachada principal, o algoritmo permite a rotação total dos modelos em torno de si mesmo em intervalos de $45^{\circ}$, viabilizando assim a análise das orientações N, S, L O, NE, NO, SE, S, inclusive na presença de obstrução vizinha.

Todas estas características são parametrizadas para dois modelos distintos, o modelo para a simulação de iluminação natural e o modelo para a simulação termo-energética.

c) Simulação de iluminação natural

Para o primeiro modelo geométrico, utilizado para a simulação de iluminação natural, considera-se as espessuras das vedações (ex.; paredes e cobertura) e as faces internas devem ter seus vetores orientados o plano de análise. Este modelo é conectado ao componente Daylight Analysis do DIVA for Grasshopper (Jakubiec e Reinhart, 2011) que realiza a simulação de iluminação natural utilizando o Radiance/ Daysim com base em uma iluminância de projeto definida no próprio componente.

d) Simulação termo-energética

Ao segundo modelo geométrico são atribuídas as características construtivas e térmicas dos materiais, bem como as cargas internas e os padrões de uso e ocupação proveniente da simulação de iluminação natural. A simulação termo-energética é realizada por meio do componente Viper, que conduz a simulação no EnergyPlus. A integração com a simulação de iluminação natural ocorre através da importação de um arquivo extensão *.csv gerado como resultado desta simulação. Este arquivo descreve o padrão de uso do sistema de iluminação artificial ao considerar a disponibilidade da iluminação natural, de acordo com determinada iluminância de projeto e determinado tipo de controle, neste caso um dimmer controlado por foto sensor.

e) Saídas (desempenho do ambiente)

Como resultado das simulações de iluminação natural são obtidos os indicadores: Autonomia da luz natural espacial para 50\% e 30\% das horas do ano; três faixas de Iluminâncias úteis para esses mesmos percentuais de horas de atendimento; Autonomia da luz natural contínua espacial para os mesmos percentuais; Fator de luz diurna espacial e o Lighting control schedule, que é endereçado para a simulação 
térmo-energética.

Da simulação termo-energética são obtidos os valores de: Consumo Energético Total; Consumo para Aquecimento, Resfriamento, Iluminação, Pessoas e Equipamentos; Ganhos Térmicos Diretos e Difusos referentes à Energia Elétrica Primária; Emissões de Carbono atribuídas ao consumo de Energia em Geral e à Energia Elétrica e Densidade de Potência de Iluminação em Uso.

\section{Gravação dos Resultados}

Os resultados tanto da simulação de iluminação natural quanto da simulação termo-energética são tratados e gravados em planilha eletrônica (Excel®). Para permitir a gravação, é necessária a utilização do Galapagos Listener, componente que verifica alterações de valor de resultados e cria uma lista ordenada a partir deles. Esta lista é então encaminhada ao componente Excel Writer do TT Tollbox responsável por gravar a planilha de Excel ${ }^{\circledR}$ com os resultados numéricos.

\section{Estudo de caso}

Como estudo de caso foram simulados três conjuntos de amostras independentes, uma com 300, outra com 200 e outra com 100 casos utilizando-se o algoritmo proposto. Estas simulações foram utilizadas para avaliar amostras que pudessem ser utilizados para modelar odesempenho energético de edifícios considerando a iluminação natural através do uso de redes neurais artificiais (RNA) (Fonseca, 2015). Para tanto, foi utilizado um processo de amostragem aleatória denominada
Hipercubo Latino (Maschio, Carvalho e Schiozes, 2009). A distribuição adotada para todas as variáveis de entrada foi a uniforme, considerando-se que cada um dos valores de entrada apresentavam a mesma frequência de ocorrência.

Essa amostragemfoi realizada no programa Matlab, utilizando como base a função lhsdesign (n,p) (The MathworksInc, 2014). A função retorna uma matriz n por p, contendo uma amostra por Hipercubo Latino de $\mathrm{n}$ valores de cada um dos parâmetros (p). Para cada coluna da matriz, os $n$ valores são distribuídos aleatoriamente para cada intervalo $(0,1 / n),(1 / n, 2 / n) \ldots,(1-1 / n, 1)$ e permutados aleatoriamente. Como saída geraram-se arquivos *.csv em que cada linha corresponde a um modelo paramétrico com as características de cada variável-chave dispostas em colunas conforme a ordem definida pelo algoritmo do Grasshopper.

Os três conjuntos amostrados foram utilizados para o treinamento, validação e teste de diferentes configurações de RNA. A adequabilidade das amostras para o treinamento de redes foi feita através da avaliação do erro absoluto percentual médio (EPAM). Para todos os testes foram simuladas três redes neurais idênticas, visando garantir que o resultado seria representativo daquela configuração de rede.

\section{Resultados}

Como principal resultado, apresenta-se o algoritmo programado para oferecer uma representação visual dos modelos (ver Figura 08) e resultados quantitativos planilhados,

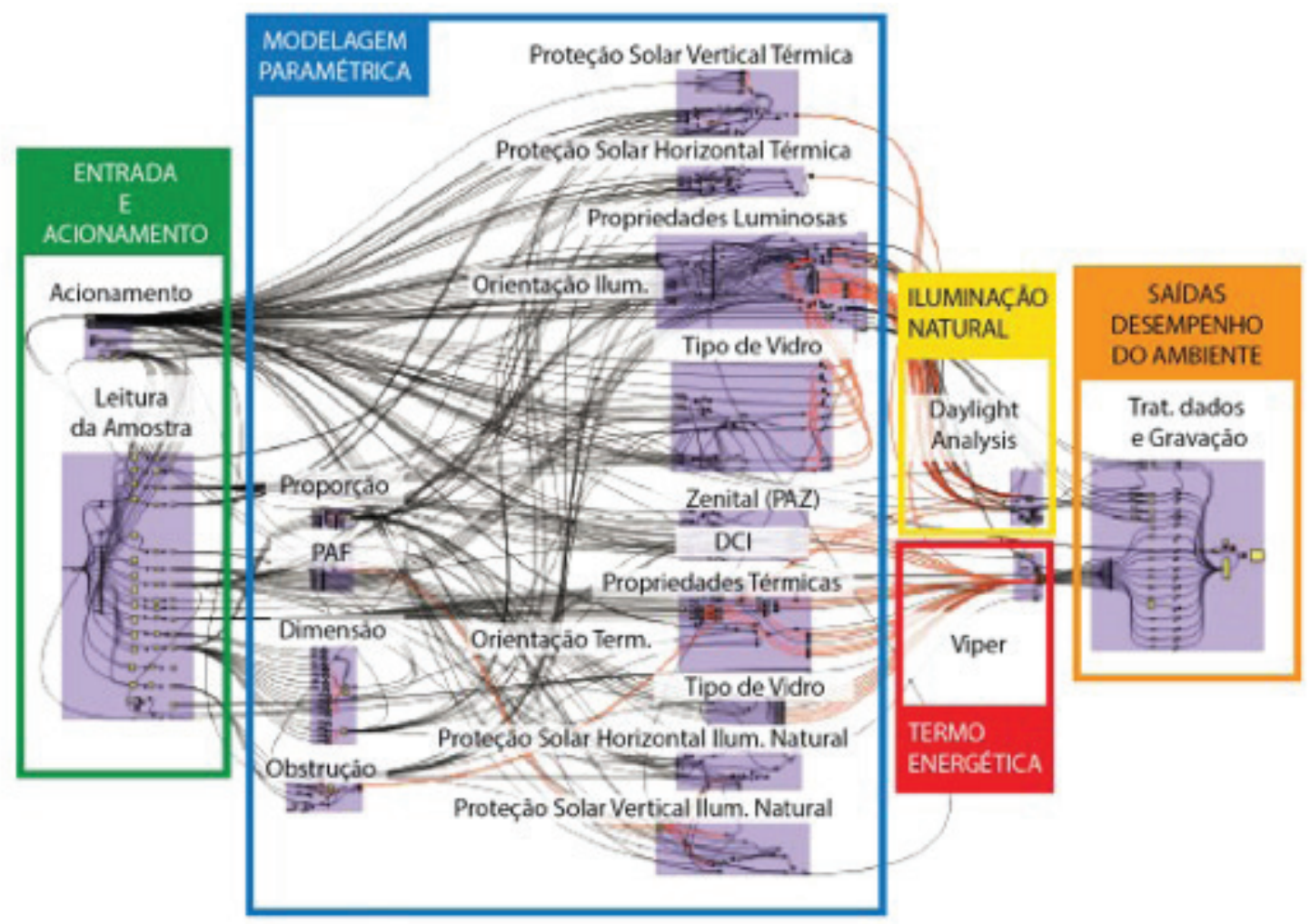

Figura 6: Algoritmo proposto no Grasshopper legendado de acordo funções de operacionalização. 
conforme descrito no Método, item e) Saídas, para a avaliação do desempenho da iluminação natural e termo-energético dos ambientes considerando-se uma zona termo-luminosa.

A Figura 06 ilustra o algoritmo, destacando em verde a área em que a amostragem é lida e a sequência de simulações é acionada; em azul, a área com as características arquitetônicas dos modelos são parametrizadas; em amarelo, onde ocorre a simulação de iluminação natural; em vermelho, onde ocorre a simulação termo-energética; e em alaranjado, onde é feito o tratamento e a gravação dos resultados.

\section{Resultados do estudo de caso}

O algoritmo proposto no Grasshopper foi utilizado para simular as três amostras independentes uniformemente distribuídas. Vale destacar que o método de amostragem Hipercubo Latino garante que cada valor de variável apareçe pelo menos uma vez nas combinações paramétricas. Como se pode observar na Figura 7 a amostra de 300 casos, em oposição ao que se esperava, foi a gerou redes com os maiores erros. Entretanto, vale ressaltar que para modelagem estatística utilizando RNA, além do tamanho da amostra, a qualidade da amostra é extremamente relevante para o desempenho final do modelo. Uma possível justificativa para este resultado é que as três amostras possuem casos diferentes, e apesar da mesma distribuição de valores de entrada, as diferentes combinações entre as variáveis de entrada podem ter gerado modelos mais complexos, o que tornou o aprendizado das RNA mais difícil, recorrendo em maiores erros no modelo estatístico.

Astrêsamostrasapresentaramresultadosdeerrosinferiores a 5\% para cada variável de desempenho individualmente, valor recomendado pela literatura de engenharia. Logo, optou-se por fazer um balanço entre o tempo de simulação, o tempo de processamento das redes e os erros resultantes para a escolha da amostra, pois os valores de erros obtidos permitiram o uso de qualquer uma das três para o treinamento das RNA. Assim, indicou-se o uso da amostra de 200 casos por ser mais conservadora que a de 100 casos e por ter apresentado erros menores e demandar menos tempo de processamento que

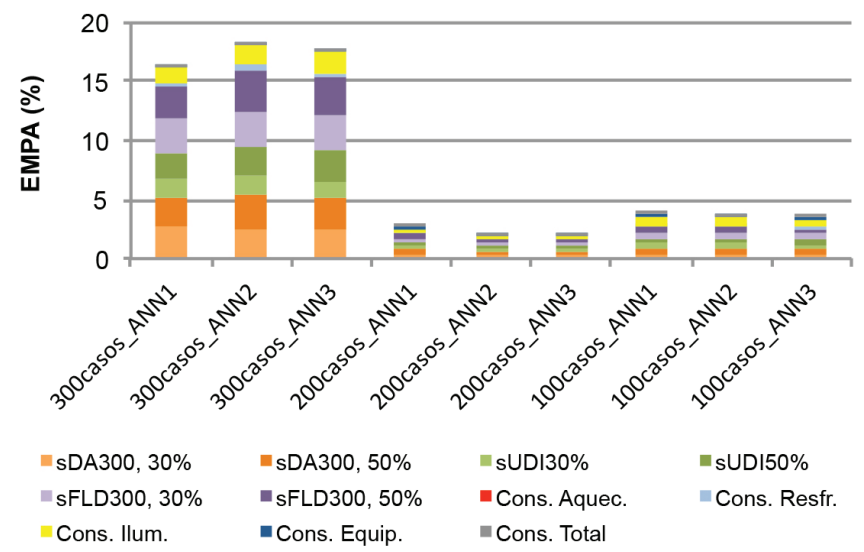

Figura 7: EPAM por variável de desempenho do ambiente para cada uma das três RNA de cada amostra. Fonte: Fonseca (2015). a de 300 casos. Esta amostra foi simulada novamente no algoritmo do Grasshopper para outras localidades, ocupações e iluminâncias de projeto permitindo o treinamento de RNAs com mais variáveis possibilitando a proposição de modelos estatísticos mais complexos (Fonseca, 2015).

\section{Conclusão}

A parametrização dos modelos através do algoritmo proposto, apesar de complexa devido ao grande número de variáveis, depois de concluída, consiste em uma potente ferramenta de simulação. Especialmente, porque permite a simulação de qualquer combinação amostrada entre as mais de 6 milhões de combinações possíveis do conjunto base de variáveis, incluindo a visualização dos modelos avaliados.

Como principal resultado, destaca-se a criação de uma ferramenta que torna possível a combinação de múltiplas variáveis as quais podem ser alteradas simultaneamente, permitindo a geração de bases de dados para avaliação do fenômeno da iluminação natural e desempenho energético, bem como a otimização de parâmetros construtivos dos modelos através do uso de algorítimos genéticos (Galapagos). Além disso, pode ser utilizada para a simulação de diferentes amostras para aplicações em metamodelagem estatística como regressão linear multivariada ou não linear, a exemplo das RNA apresentadas neste trabalho.

Com o algoritmo de parametrização reduziu-se o tempo da preparação dos modelos de simulação do estudo de caso, descartando a necessidade modelar todas as combinações de geometria e demais variáveis. Da mesma forma, ganhou-se tempo na integração entre simulações de iluminação natural e térmica, uma vez que o processo de endereçamento do arquivo do padrão de uso do sistema de iluminação artificial gerado pelo Daysim (Lighting Control Schedule) foi préprogramado. O processo de preparação dos 200 casos, que através procedimento usual levaria em torno de 40 horas para ser realizado, pôde ser realizado pelo algoritmo em cerca de 10 minutos. Além disso, a possibilidade de visualização dos modelos no Rhinoceros aumentou a compreensão acerca da geometria dos modelos amostrados enquanto a realização das inúmeras simulações sequencialmente em batch, bem como a gravação de seus respectivos resultados, evitou eventuais falhas humanas no processo.

Concluiu-se assim que a utilização de algoritmos de parametrização para modelar as principais variáveischave de iluminação natural e simular o seu desempenho é uma ferramenta eficiente e importante para o auxílio no processo projetual, assim como no desenvolvimento de pesquisas científicas. A ferramenta viabilizou a avaliação de diversas configurações arquitetônicas em menor tempo e com maior facilidade de aplicação do que os métodos de simulação tradicional.

\section{Referências}

Choo, T. S., \& Janssen, P. (2013). Semi-transparent building 
integrated photovoltaic facades: Maximise energy savings using evolutionary multi-objective optimisation. In Proceedings of the 18th International Conference on Computer-Aided Architectural Design Research in Asia (CAADRIA 2013) (pp. 127-136). Singapore.

Crawley, D. B., et al. EnergyPlus: creating a new-generation building energy simulation program. Energy and Buildings, v.33, n.4, p.319-331. 2001.

Didoné, E. L. A influência da luz natural na avaliação da eficiência energética de edifícios contemporâneos de escritórios em Florianópolis/SC. . Arquitetura e Urbanismo, Universidade Federal de Santa Catarina, Florianópolis, 2009. $174 \mathrm{p}$.

Fonseca, R. W. Iluminação natural e consumo energético de edificações não residenciais: aplicação de redes neurais artificiais. (tese de doutorado) Departamento de Engenharia Civil, Universidade Federal de Santa Catarina, Florianópolis, 2015. 350 p. No prelo.

Gagne, J. M. L., \& Andersen, M. (2010). Multi-objetive facade optimization for daylighting design using a genetic algorithm. In SimBuild (pp. 110-117). New York City, New York.

Gagne, J. M. L., \& Andersen, M. (2010). Multi-objetive facade optimization for daylighting design using a genetic algorithm. In SimBuild (pp. 110-117). New York City, New York.

Giani, M., Belfiore, C., Lobaccaro, G., Masera, G., Imperadori, M., \& Frontini, F. (2013). A Design approach for the solar optimization of built volumes. In CISBAT 2013 (pp. 8-11). Lausanne, Switzerland.

Heshong, L. Daylight Metrics. Heshong Mahone Group - Public Interest Energy Research - California Energy Commission fevereiro de 2012, p.387. 2011. (CEC-500-2012-053)

Jakubiec J. A. e Reinhart, C. The Adaptive Zone - A Concept for Assessing Glare Throughout Daylit Spaces. In: Proceedings of Building Simulation, 12th Conference of International
Building Performance Simulation Association. Sydney, 2011. 14-16 p.

Lobaccaro, G., \& Masera, G. (2014). A Digital Language for a New Sustainable Urban Planning: Design and Simulation Tools for Solar Architecture. In Buinding Simulation and optimization (p. 8).

Maschio, C., Carvalho, C. P. V. e Schiozes, D. J. Aplicação da técnica de hipercubo latino na integração do ajuste de histórico com a análise de incertezas. 5 Congresso Brasileiro de Pesquisa e Desenvolvimento em Petróleo e Gás. Fortaleza/ Ceará: Associação Brasileira de P\&D em Petróleo e Gás 2009.

McNeel, R. e Associates. Rhinoceros 3D. v. 5.Rhinoceros 3D é um programa de modelagem tridimensional baseado na tecnologia NURBS.2014

Ramos, G. e Ghisi, E. Avaliação do cálculo da iluminação natural realizada pelo programa EnergyPlus. Revista Ambiente Construído, v.10, n.2, p.10. 2010.

Reinhart, C. F. e Walkenhorst, O. Validation of dynamic RADIANCE-based daylight simulations for a test office with external blinds. Energy and Buildings, v.33, n.7, p.683-697. 2001.

The Mathworks INC. MATLAB CENTRAL: File Exchange Disponível: <http://www.mathworks.com/matlabcentral/ fileexchange>. Acesso em: 4 de junho de 2014.

Torres, S. L., \& Sakamoto, Y. (2007). Facade design optimization for daylight with a simple genetic algorithm. In Building Simulation (pp. 2003-2008).

Vannini, V. C. (2011). Otimização geométrica de dispositivos solares de fachada. UFRGS.

Versage, R., Melo, A. P. e Lamberts, R. Impact of different daylighting simulation results on the prediction of total energy consuption. SimBuild 2010 - Fourth National Conference of IBPSA-USA. New York: IBPSA 2010. 